\title{
sciendo
}

\section{CHARACTERISTICS OF JUVENILE DELINQUENCY WITH SPECIAL EMPHASIS ON JUVENILES AS CHILD SEXUAL ABUSERS}

\author{
Asst. Prof. Vedije Ratkoceri \\ Criminal law and security, Law Faculty, \\ South East European University, Tetovo, North Macedonia \\ v.ratkoceri@seeu.edu.mk \\ PhD. Asst. Ebru Ibis \\ Law Faculty, European University Skopje, Skopje, \\ North Macedonia \\ ebru.ibis@eurm.edu.mk
}

\begin{abstract}
The paper is composed of two parts. The first part covers juvenile delinquency with all its characteristics. When analyzing the delinquency, we gave a special place to the sociopathological phenomena which is more and more present and the rate is higher from year to year. Social pathology is a huge issue that requires special commitment, first, for its detection and then prevention. Within the delinquency, we also cover the most common crimes committed by juveniles.

In the second part of this paper, the authors deal in more details with a specific form of crime which can also be committed by juveniles: child sexual abuse and pedophilia. First, the difference between child sexual abuse and pedophilia will be discussed, a difference that is of particular importance in cases where minors are abusers. Furthermore, the main characteristics of cases when both perpetrators and victims of sexual abuse are minors will be addressed. Although these criminal offenses are rarer in practice unlike the criminal offenses and deviant behaviors treated in the first part, however, knowing the main characteristics and
\end{abstract}


specifics of such cases is of particular importance for the legal-criminal treatment of the perpetrators of these criminal offenses.

Key words: juvenile delinquency, youth gang, social pathology, child sexual abuse, pedophilia

\section{INTRODUCTION}

Delinquency is a synonym for juvenile offenders. It is important to emphasize that delinquency is a heterogeneous phenomenon, as well as one of the key problems of modern societies which shows a growing trend in the past few years. One of the most important issues regarding juvenile delinquency that should be emphasized is that delinquency should be distinguished from crime because delinquency is more complex phenomena and covers: misdemeanors, crimes, and social pathological phenomena. Delinquency is often defined as a social disease because delinquents are considered as persons who do not live in accordance with moral and positive norms. Modern theories in the field of juvenile criminal law and juvenile delinquency claim that the juvenile is not born as a delinquent and does not decide to become a delinquent but there are several external factors that influence the creation of a delinquent profile as well as the influence of multifactorial theories of delinquency. In this paper, we have specifically covered the problem of children as sexual abusers. Child sexual abuse is undoubtedly one of the most serious crimes that threaten the life, health, and integrity of children. The psychological consequences of childhood sexual abuse accompany the victim throughout life and are severe and often irreversible. In cases where child abusers appear to be adults, the approach from states and legal legislations is harsh providing for long-term prison sentences, medical pharmacological treatments, psychological treatments, special registers for the identification of these persons and so on. However, when child abusers are children themselves or rather said juveniles, then due to the characteristics of juveniles which will be elaborated in this paper, such a criminal policy that applies to adults cannot be applied to juveniles in sexually abusing children. Precisely this issue is the topic of elaboration in the second part of this paper. However, let us first investigate the general characteristics of juvenile delinquency. 


\section{CHARACTERISTICS OF JUVENILE DELINQUENCY}

In the last decade the situation regarding juvenile delinquency globally is becoming more serious and shows a growing trend. It is not easy to give a complete and generally accepted definition of this phenomenon, because in different countries juvenile delinquency is linked to different factors. It is the same type of criminal behavior as in adults, but with special features such as: underdevelopment of the mental structure of the juvenile, immaturity, and age as the main determinants of different treatment of this phenomenon. We mentioned that delinquency includes misdemeanors, crimes, and social pathological phenomena. Within the mentioned categories we will especially emphasize the criminal acts and the part with the socio-pathology. Generally, most common crimes committed by juveniles are:
a) crimes against property
b) crimes against life and body
c) crimes against sexual freedom and morality
d) crimes against the public order and
e) crimes against traffic safety

In the last decade socio-pathological phenomena show a high prevalence of juvenile offenders, especially alcoholism, drug addiction, prostitution, gambling, vagrancy, and internet mania. According to numerous studies, alcoholism is associated with committing various crimes such as: murders, bodily injuries, robberies, slander, harassment of family members, rape, crimes against property etc. In the Republic of North Macedonia, the most common crimes committed by juveniles who use alcohol are crimes against property, crimes against sexual freedom and sexual morality (sexual abuse and rape as a crime), crimes against life and body - in this part we will especially mention: bodily injuries, participation in a fight as the most characteristic crime committed by juveniles under the influence of alcohol as well as traffic offenses. Taking in consideration the connection between juvenile delinquents alcohol users and traffic delinquency, the German criminologist Günter Kaiser uses the term "traffic drunkenness" which in recent years shows an increase especially among juveniles which are participants in traffic under the influence of alcohol.

According to Goldstein: "drug addiction (substance use) is defined as a chronic, relapsing disorder characterized by compulsive drug seeking and use despite adverse consequences. It is considered a brain disorder, because it involves functional changes to brain circuits involved in reward, stress, and self-control. Those changes may last a long time after a person has stopped taking drugs" (Goldstein RZ, 2011). "Drugs lists several 
drug addiction risk factors: aggressive behavior demonstrated in childhood, lack of supervision by parents, low peer refusal skills, experimentation with drug, drugs available in schools, and poverty of the community. Furthermore, Drugs also lists some protective factors which, by definition, oppose the risk factors, such as: self-efficacy (belief in self-control), parental monitoring and support, positive relationships, extracurricular activities, school antidrug policies, neighborhood resources." (Drugs, Brains, and Behavior: The Science of Addiction, National Institute on Drug Abuse, 2020).

In the criminological literature, drug addiction is often associated with drug crime, which is the most common form of organized crime. The impact of drug addiction on juvenile delinquency is enormous; a worrying fact is that the percentage of juveniles using narcotics and psychotropic substances is increasing. In order to go deeper into the causes of drug addiction of juveniles, we should consider especially the reasons that push the juveniles on the street life, such as: migrations; economic factors; earning money; peer influence; child neglect; family violence; abuse; family imbalance, urbanization, the impact of street culture and the possibility for free behavior of the child etc.

In the last years, the situation of "blowing glue" as a kind of inhalation by juveniles is becoming more and more frequent, while showing an aggressive and violent attitude towards the environment that is manifested. The reason why juveniles are blowing glue is simple, first, they do not have enough money to buy another kind of drug and second the dose they receive through the glue satisfies them and that is why using glue as an inhalation is becoming more widespread especially for juveniles who live in streets and are involved in vagrancy. How do juveniles come into contact with drugs? If we exclude the example with the family as a micro group, in the Republic of North Macedonia juveniles most often come in contact with drugs in high school, where they are offered free drugs near the school in order to get them after a certain time of using and buying drugs.

It is important to explain the whole procedure for using drugs, moreover, the term known as a "drug scene" which describes the drug subculture, behavior, attitudes, and way of dressing members of the marginal group of addicts.

Juvenile prostitution is socio-pathological problem that most often involves juveniles as victims of sexual abuses. Juveniles involved in prostitution are victims of sexual abuse, many of them, especially in underdeveloped countries, are often sexually abused by their families and even their parents. This situation results with finding ways to existence on the 
street, which in turn leads to delinquent activities. In the American criminology literature, there is a special term called "survival sex" it describes the impact of prostitution on juvenile delinquency and child prostitution. According to Estes \& Neil: "Many youngsters involved in the exchange of sex for money or other considerations (e.g., food, shelter, drugs, etc.) do not perceive themselves as engaging in prostitution but rather as doing "whatever is necessary" to ensure their survival” (Estes \& Neil, 2001).

The authors also would like to emphasize gambling, which is very common in recent years among juveniles and appears as one of the reasons for creating a delinquent profile. It is worrying that juveniles aged 10-15 have already had gambling experience. The reasons behind this are: lack of parental supervision, visiting websites related to gambling, availability of online gambling, free gambling applications, sponsored social media advertisings about gambling etc.

Another socio-pathological problem that shows a growing tendency is vagrancy. For the first time, the term vagabond from a legal point of view is defined in Article 270 of the French Codè Penal from 1910. Juveniles which are involved in vagrancy can be defined as a people who have not integrated into society, have a negative attitude towards labor and creativity, hence they provide their personal existence with criminal and delinquent actions. One of the important categories that we analyze within the vagrancy is begging (or well known as a panhandling) of juveniles, which is very widespread in Republic of North Macedonia.

Unfortunately, in RNM there is no statistical database that could monitor the rate of juvenile begging; this situation leads to difficulties in monitoring and preventing this phenomenon. The most common characteristics of begging children are as follows: they are not usually included in the educational system, they show aggression towards other people, they often commit property crimes or robberies, they are homeless, and many of them are stateless. In short, these children from a very early age have a predisposition to build a delinquent profile and spread the delinquent infection.

The other socio-pathological phenomenon that we have covered in this paper is internet mania. In our opinion, although Internet mania (Internet addiction) sounds like a completely normal phenomenon, in terms of the degree of risk, if we take into account the fact that we are talking about juveniles which are in the period of puberty, we consider it the riskiest because Internet mania indirectly is connected with: gambling, prostitution, drug 
trafficking, conscious use of websites with negative content such as: violence, pornography, video game addiction, etc. This condition causes juveniles to become trapped in the world of the antisocial behavior, aggressive attitude, lack of attendance at school, impaired communication with peers, networking with strangers in the virtual world, and even consequences for mental health.

In addition to these behaviors and offenses which we elaborated above, juveniles tend to commit some more specific offenses. Such is the case with criminal offenses of sexual abuse and especially child sexual abuse. In the criminological literature, when it comes to sexual abuse, in the most cases children and women are often shown in the position of victims, but there are cases when juveniles sexually abuse children.

The law makes an additional distinction between children and juveniles. In the criminal justice system, a person is considered to be a child when, by virtue of his or her immaturity, he or she cannot be held to be responsible for criminal behavior. In most Western jurisdictions, a person younger than 12 years of age is considered to be a child. By definition, then, children cannot be sex offenders because they have not been convicted of a sexual crime. In other way, if a person has been convicted of a sexual crime, the convicting court did not regard him or her as a child. When children engage in sexual behaviors that would be regarded as criminal when they are older, they are described as "children with sexual behavior problems" (Grey, Busconi, Houchens, \& Pithers, 1997) cited (Barbaree \& Marshall, 2006).

Moreover, the young people between the ages of 12 and 18 either officially charged with a sexual crime, such as child molestation, rape, exhibitionism, or voyeurism, have performed an act that could actually be officially charged, or committed sexually abusive or sexually aggressive behavior, or an actual sexual act with a person of any age against their will or in an aggressive, exploitative, or threatening manner are called juvenile sexual offenders or juvenile sex offenders. Similarly, young people choosing only or primarily child victims younger than them as offenders are called child molesters (Gerardin and Thibaut 2004; Miner et al. 2006) cited by (Thibaut et al, 2016). It is an undisputable fact the greater number of the sexual assaults are committed by men in their adulthood; yet a significant minor percentage of sexual assaults (approximately 20\%) are committed by juveniles (Barbaree \& Marshall, 2006).

However, before treating minors as child sexual abusers, let us first look at the main features of child sexual abuse and pedophilia. 


\section{CHARACTERISTICS OF CHILD SEXUAL ABUSE AND PEDOPHILIA}

Child sexual abuse is present in all countries of the world and is a complex product of many social, cultural, economic, and biological factors. As a serious crime it constitutes one of the most brutal and serious violations of the life and health of children. This heinous crime has long-term and serious consequences for both the victim and her family, given that it is an immature individual (child) and in the developmental stage. One of the basic rights of children is to protect them from abuse, especially sexual abuse. Therefore, in general all of us, including state institutions, family and society have a duty to protect children and provide a living environment that will protect, care, and educate them.

In everyday vocabulary, child sexual abuse is also referred to by the term pedophilia and individuals who commit child sexual abuse are called pedophiles (Ratkoceri V. 2017). However, the medical and psychological literature highlights obvious differences between these two notions (Ratkoceri V. 2017). Moreover, pedophiles are considered as individuals who have a certain mental disorder - paraphilia, while the term child sexual abuse includes all other individuals who sexually abuse children but not because they suffer from the mental disorder - paraphilia but because they commit the abuse for other reasons (for example: criminal reasons). Pedophiles are just a category of child sexual abusers.

In addition, "pedophilia is a clinical diagnosis usually made by a psychiatrist or psychologist. It is not a criminal or legal term, such as forcible sexual offense, which is a legal term often used in criminal statistics" (Hall \& Hall, 2007). Therefore, in the legal sense, what is considered child sexual abuse depends on the respective incrimination of each legislation separately and the respective age that the legislation has set as the dividing line of who is considered a child. Thus, for example, according to the Criminal Code of the Republic of North Macedonia, child sexual abuse is incriminated in the criminal offense - Sexual abuse of children under 14 years of age - Article 188. The offense of "sexual assault against a child who has not attained 14 years", it is considered that it is done by someone who will perform sexual intercourse or other action against a child who has not attained 14 years and will be sentenced to at least 12 years of imprisonment (Article 188, paragraph 1- Criminal Code of RNM). The second paragraph further provides the most severe form of this offense, stating that if due the action performed as described in paragraph 1 is caused grievous bodily harm, 
death or other serious consequences or if the offense is committed by several persons or in a cruel and degrading manner, the perpetrator will be sentenced by at least 15 years imprisonment or life imprisonment (Article 188, Criminal Code of RNM, Official Gazette of RNM No. 27/2014). According to the professor Kambovski (2015),' the object of protection of this crime is the right development of children up to age 14, which means fully protection from various forms of sexual abuse (pedophilia) and by abnormal influences on their formation as healthy individuals (Kambovski, 2015). ”Therefore, criminal law includes principle prohibition to any sexual relationship with children who have not attained 14 years, regardless of gender. Sexual intercourse or other sexual action either willingly or by force are also incriminated, so the child agreement to such relationships has no value since the child this age cannot form free will." (Kambovski, 2015).

Taking in consideration all these facts, not all people who commit sexual crimes against children are pedophiles, although all could be termed sex offenders or child molesters (Moog, 1999). This is because there are cases when a person who commits sexual violence involving children, his behavior or fixation on children is short-lived (Winslade, Stone, Smith-Bell, \& Webb, 1998) or driven by other purposes.

According to the diagnostic criteria of the Diagnostic and Statistical Manual of Mental Disorders, Fourth and Fifth Edition, a pedophile is ' an individual who fantasizes, is sexually aroused or experiences sexual arousal towards adolescent children (generally younger than 13 years) for a period of at least 6 months" (DSM - $5^{\text {th }}$ ed., American Psychiatric Association 2013). So, according to this Manual, pedophilia is listed as a mental disorder.

The apostrophized guide, which is emphasized by most of the literature in the field related to pedophilia, also defines the criteria that must be met in order for an individual to be considered a pedophile. First, it should be an impairment lasting at least 6 months, with recurrent and intense sexually arousing fantasies, sexual urges, or behaviors that involve sexual activity with a prepubescent child or children (generally age 13 years or younger); second, fantasies, sexual urges, or behaviors that cause clinically significant distress or impairment in social, occupational, or other important areas of functioning; and, the impaired person is at least aged 16 years, and at least 5 years older than the child or children (Winslade, Stone, Smith-Bell, \& Webb, 1998).

From these criteria related to pedophilia we can conclude that a person who sexually abuses a child aged under 13 or 14 years old will be considered a pedophile and not the 
person who abuses a minor aged from 14 or 15 years to 18 years old (hence is a juvenile abuser but not a pedophile). Second, the age difference between the child victim and the abuser must be at least 5 years, and third, the person under the age of 16 is not considered a pedophile (while this person may be a child sexual abuser).

\section{JUVENILES AS CHILD SEXUAL ABUSERS}

Although research suggests a potential link between pedophilia and the commission of the crime of child sexual abuse since younger age, when child sexual abuse is committed by a minor, we must keep in mind that such a perpetrator is not always considered a pedophile. This is because as mentioned above according to the DSM one of the conditions that must be met in order for a person to be considered a pedophile is that "the person with the disorder must be at least 16 years old and at least 5 years older than the abused child" (DSM - IV). The age qualifier is added to eliminate developmentally normal childhood sex play (eg, two 8-year-olds "playing doctor"). Nevertheless, by this definition, a 13-year-old who touches an 8-year-old would be considered a child molester but would not meet criteria to be a pedophile (Johnson, 2002) cited by (Hall \& Hall, 2007). However, data from the study by Abel and Harlow showed that " $40 \%$ of child molesters, who were later diagnosed as having pedophilia, had molested a child by the time they were 15 years old' (Abel \& Harlow, 2001).

The NIBRS (National Incident-Based Reporting System) data on juvenile sexual assaults found that " $40 \%$ of assaults against children younger than 12 years were committed by juveniles, with the most frequent age of the offenders being 14 years old" (Hall \& Hall, 2007). Historically, sexual abuse and molestation of children by teens has been labeled "curiosity" or "experimentation," and many sexual offenses have been termed "adolescent adjustment reactions (Vizard, 1995) cited by (Winslade, Stone, Smith-Bell, \& Webb, 1998).

The field literature enumerates several factors that influence the commission of these criminal offenses by juveniles/minors. Specifically, adolescent male sex offenders repeatedly exhibit a history of delinquency and psychiatric impairment before their first sexual offense; severe family problems; separations from parents and placements away from home; neglect and abuse, both physical and sexual; social awkwardness or isolation; academic or behavioral problems at school; low IQs; psychopathology, including primarily neurotic, conduct, and personality disorders; and neurological impairment (Saunders \& Awad, 1988) cited by (Winslade, Stone, Smith-Bell, \& Webb, 1998). 
Furthermore, the heterogeneous nature of the juvenile sexual offender population is due in part to the fact that these offenders are still children. Being children, they continue to grow and learn, continue to internalize social experiences, and continue to develop in a cognitive and moral sense. The sexually abusive behaviors may be tied to the juvenile's continuing experimentation with sexual practices, and the lack of a firmly established pattern of normal sexual arousal. These attributes may contribute to better treatment outcomes on juveniles (Poortinga, Newman, Negendank, \& Benedek, 2009). According to Hall, ”in cases that involve adolescent offenders, factors such as emotional and sexual maturity should be considered before a diagnosis of pedophilia is made", (Hall \& Hall, 2007).

In addition, certain psychological treatments, and not pharmacological treatments (chemical castration) are provided for the treatment of juveniles as child sexual abusers. The impact these drugs have on the sexual development of minors (juveniles) is controversial because medical drugs used for chemical castration have only been researched and studied in adult sexual abusers. Moreover, these drugs, are not recommended for individuals younger than 25 years old and most of the criminal legislations of different countries have set a certain age limit (which is not lower than 18 years of age) of perpetrators against whom chemical castration cannot be imposed.

\section{CONCLUSIONS}

In this paper we determine that delinquency is a complex phenomenon. Moreover apart from the crimes and misdemeanors, we found that the socio-pathological phenomena showed a huge impact on the increase of the juvenile delinquency rate, especially the phenomena such as: alcoholism, drug addiction, prostitution, gambling, begging and child sexual abuse. Through the research we concluded that the number of begging children is serious, but unfortunately, we do not have any official data on the total number of begging children in the Republic of North Macedonia, so it is also necessary to monitor this phenomenon and set up a statistical base in order to further create prevention programs around begging, alcoholism, prostitution, as well as gambling.

One of the important recommendations regarding this paper is the establishment of a statistical database for certain socio-pathological phenomena that are most common. The reason is the following: the number is constantly growing, the delinquent infection spreads rapidly and infects even non-delinquent juveniles, monitoring this phenomenon without a statistical database is almost impossible, setting up prevention programs without data would 
be unsuccessful. As we mentioned above prevention is the most important part of all activities in field of juvenile delinquency. Furthermore, successfully implemented prevention program, properly set prevention goals especially around primary and secondary prevention will result in reduced delinquency rate.

Concurrently, regarding juveniles as child sexual abusers, we also have reached some conclusions. First, we must be clear that a child victim of sexual abuse is considered a person under the age of 14 (according to the Criminal Code of RNM, in some countries the limit is set even below, at the age of 13 or 12) and juvenile sexual abuser is considered a perpetrator from the age of 14 to the age of 18 years. Another important element for sexual activity between the perpetrator and the victim, which must be at least 5 years apart that have no criminal intent behind (except in cases where the abuse is committed using violence and force against a child under the age of 14). Therefore, we recommend that in the Criminal Code of the Republic of Northern Macedonia, in the chapter of criminalization of criminal offenses of a sexual nature against minors, to add a point where it decriminalizes this behavior, respectively not to be considered a criminal offense the sexual intercourse with agreement between two minors who have reached the age of 14 and who do not have more than two (2) years of age difference.

Another important element in cases where a child sexual abuser is a minor is that according to the criteria defined and elaborated in this paper, he/she cannot be considered a pedophile, therefore treatments and methods that are applied to adults (pedophiles), such as medical-pharmacological treatment (chemical castration), psycho-therapeutic treatment, etc., cannot be applied.

Additionally, considering that in the Criminal Code of the RNM (starting from 2014), medical-pharmacological treatment (chemical castration) is provided as treatment for sexual abusers of children under 14 years of age, we propose that to the next amendments of the Criminal Code to incorporate the norm according to which this treatment cannot be applied to perpetrators under the age of 25 , as recommended by the literature and scientific research conducted in this regard. 


\section{REFERENCES}

1. Barbaree H, Marshall W (2006). An introduction to the juvenile sex offender - terms, concepts, and definitions, Second edition, The Guildford Press, New York

2. Diagnostic and Statistical Manual of Mental Disorders, DSM-5 (5th edn, American Psychiatric Association 2013)

3. Drugs, Brains, and Behavior: The Science of Addiction (2020), National Institute on Drug Abuse; National Institutes of Health; U.S. Department of Health and Human Services

4. Estes, Richard J.; Weiner Alan Neil, (2001) „,The Commercial Sexual Exploitation of Children in the U. S., Canada and Mexico "Philadelphia: University of Pennsylvania

5. Florence Thibaut, John M. W. Bradford, Peer Briken, Flora De La Barra, Frank Häßler, Paul Cosyns \& on behalf of the WFSBP Task Force on Sexual Disorders (2016) The World Federation of Societies of Biological Psychiatry (WFSBP) guidelines for the treatment of adolescent sexual offenders with paraphilic disorders, The World Journal of Biological Psychiatry, 17:1, 2-38, DOI: $10.3109 / 15622975.2015 .1085598$

6. Goldstein RZ, Volkow ND. (2011) Dysfunction of the prefrontal cortex in addiction: neuroimaging findings and clinical implications. Nat Rev Neurosci.

7. Hall, R. C., \& Hall, R. C. (2007). A Profile of Pedophilia: Definition, Characteristics of Offenders, Recidivism, Treatment Outcomes, and Forensic Issues. Mayo Clin Proc. 2007;82(4), 457-471.

8. Harrison, K., Manning, R., \& McCartan, K. (2010). Current multidisiplinary definitions and understendings of padophilia. Social and Legal Studies (19) 4, 481496.

9. Kambovski, V. (2015). Komentar na Krivicniot Zakonik na Republika Makedonija (Vol. II). Skopje: Matica.

10. Law on Amendments and Addendums of the Criminal Code, Official Gazette of Republic of Macedonia No. 27.2014

11. Moog, A. (1999). California Penal Code Section 645: Legislators Practice Medicine on Child Molesters. 15 J. Contemp. Health L. \& Pol'y 711-737

12. Poortinga, E., Newman, S. S., Negendank, C. E., \& Benedek, E. P. (2009). Juvenile Sexual Offenders: Epidemiology, Risk Assessment, and Treatment. In F. M. Saleh, A. J. Grudzinskas, J. M. Bradford, \& D. J. Brodsky, Sex offenders - Identification, Risk Assessment, Treatment, and Legal Issues (fv. 221-241). Oxford, New York: Oxford University Press.

13. Ratkoceri, V (2017). Chemical castration of child molesters - Right or Wrong?!. European Journal of Social Sciences Education and Research - EJSER, Vol.11 (1), pp. 70-76 
14. Winslade, W. T., Stone, H., Smith-Bell, M., \& Webb, D. M. (1998). Castrating Pedophiles Convicted of Sex Offenses against Children: New Treatment or Old Punishment, 51 SMU L. Rev. 349 (1998), 351-410

15. https://www.justice.gov

16. https://smallwarsjournal.com

17. https://www.drugabuse.gov 